\title{
Prediksi Jumlah Penjualan Produk di PT Ramayana Pematangsiantar Menggunakan Metode JST Backpropagation
}

\author{
Muhammad Syafiq, Dedy Hartama, Ika Okta Kirana, Indra Gunawan, Anjar Wanto \\ Program Studi Sistem Informasi, STIKOM Tunas Bangsa, Pematangsiantar, Indonesia \\ email : ${ }^{* 1}$ muhammadsyafiq4567@gmail.com \\ Submitted 15-01-2020; Accepted 03-02-2020; Published 15-02-2020
}

\begin{abstract}
Abstrak
Produk adalah salah satu hal yang paling penting dalam hal bisnis terutama bagi industri ritel. Ramayana adalah salah satu tempat yang paling bagus untuk penjualan produk-produk baik itu berupa makanan maupun minuman. Pada tahun 2012-2018, jumlah penjualan produk-produk di Ramayana mengalami kurva naik turun. Hal itu bisa mengakibatkan laba rugi bagi Ramayana, untuk menghindari hal tersebut perlu diadakan sebuah prediksi untuk tahun-tahun berikutnya agar pihak Ramayana dapat mengetahui apa yang akan terjadi di tahun-tahun berikutnya dalam penjualan poduk dan dapat mengambil suatu langkah untuk lebih efektif dalam menjual produkproduknya. Data yang digunakan dalam penelitian ini adalah data laporan tahunan penjualan produk yang bersumber dari Ramayana dari tahun 2012 sampai dengan tahun 2018. Penelitian ini menggunakan metode jaringan syaraf tiruan Backpropagation dengan menggunakan 5 arsitektur yaitu 3-26-1, 3-31-1, 3-35-1, 3-39-1 dan 3-40-1. Arsitektur yang terbaik adalah 3-35-1 dengan tingkat akurasi 92\%. Hasil yang diperoleh adalah hasil prediksi jumlah penjualan untuk tahun 2019, 2020, 2021, dan 2022.
\end{abstract}

Kata Kunci: Produk, Ramayana, Prediksi, JST, Backpropagation.

Abstract

Product is the one of thing which more important in the business especially for the retail industry. Ramayana is the one exact place for selling retail products such as clothing, shoes, or slipper. On 2012-2018, the number of sales of products in Ramayana experience curve up and down. That thing can cause profit and lose for Ramayana, to avoid that thing need to be held a prediction for the next months so that Ramayana side can know what will happen in the next months in selling it's product and can take a step for more effective in selling it's products. The data which used in this research is the data report monthly product sales of shoes \& sandal sourced from Ramayana from 2012 until 2018. This research uses the Backpropagation neural network method using 5 architectures namely 3-26-1, 3-31-1, 3-35$1,3-39-1$ and 3-40-1. The best architecture is 3-35-1 with an accuracy rate of $92 \%$. The results obtained are the results of the prediction of the number of sales for 2019, 2020, 2021 and 2022.

Keywords: Product, Ramayana, Prediction, Artificial Neural Network, Backpropagation

\section{PENDAHULUAN}

Penjualan adalah transaksi yang pertama dan terpenting antara penjual dengan pembeli dimana uang ditukar dengan barang atau jasa. Penjualan merupakan aktivitas yang sering dilakukan dimana saja dan kapan saja baik itu di toko, pasar tradisional, supermarket dan sebagainya. Penjualan ini bertujuan untuk meningkatkan bisnis pembeli, maksudnya apabila suatu perusahaan tidak meningkatkan produknya baik itu dalam segi versi maupun kualitasnya maka pembeli tidak akan berniat untuk membeli produk tersebut. Itu mengapa perusahaan-perusahaan selalu meningkatkan produk-produk mereka untuk menarik minat pembeli terutama perusahaan-perusahaan di Indonesia.

Indonesia sebagai negara yang berkembang memiliki banyak perusahaan-perusahaan maupun industri yang berdiri di seluruh daerahnya, salah satu yang paling besar adalah industri ritel. Industri ritel di Indonesia saat ini semakin berkembang dengan semakin banyaknya pembangunan gerai-gerai baru di berbagai tempat [1]. Salah satu tempat perdagangan industri ritel adalah Ramayana Plaza. Ramayana plaza adalah jaringan toko swalayan yang memiliki banyak cabang di Indonesia. Selain department store yang menjual produk sandang seperti baju dan sepatu, Ramayana juga memiliki supermarket atau pasar swalayan yang menjual kebutuhan pangan dan sehari-hari [2]. Ramayana memiliki visi \& misi untuk menjadi peritel terbesar di Indonesia dengan memberikan kualitas produk yang tinggi kepada konsumen. Pada tahun 1999 Ramayana didirikan di kota Pematangsiantar dan masih beroperasi sampai saat ini dengan perkembangan yang besar dan pengunjung yang sangat banyak tiap bulannya.

Akhir-akhir ini Ramayana Pematangsiantar sedang mencoba untuk meningkatkan jumlah penjualan produkproduknya agar tidak mengalami kerugian yang besar bagi perusahaan serta menutup kerugian atas terbakarnya Ramayana pada tahun 2009. Namun sebelum hal itu terjadi jumlah penjualan Ramayana tidak akan mengalami peningkatan sehingga akan menimbulkan dampak negatif kepada Ramayana Pematangsiantar. Dampak dari tidak meningkatnya penjualan produk di Ramayana ialah target penghasilan marketing yang tidak dapat tercapai. Maka untuk itu perlu dilakukan sebuah penelitian berupa prediksi agar dapat mengetahui berapa jumlah penjualan produk-produk Ramayana yang terprediksi di tahun yang akan datang. Metode yang akan digunakan untuk membantu proses prediksi adalah Backpropagation. Backpropagation adalah algoritma pembelajaran untuk memperkecil tingkat error dengan cara menyesuaikan bobotbobotnya berdasarkan perbedaan output dan target yang diinginkan.

Backpropagation adalah metode pembelajaran jaringan syaraf tiruan yang umum digunakan. Backpropagation bekerja melalui proses secara teratif dengan menggunakan sekumpulan contoh data (data training), membandingkan nilai prediksi dari jaringan dengan setiap contoh data. Backpropagation digunakan pada jaringan multi-layer yang dapat terdiri atas beberapa hidden unit, dan bertujuan untuk meminimalkan error pada output yang dihasilkan oleh jaringan [3]. 
Adapun tujuan penelitian ini dilakukan untuk mengimplementasikan metode jst backpropagation dalam memprediksi jumlah penjualan produk-produk Ramayana Pematangsiantar di tahun berikutnya.

\section{METODE PENELITIAN}

\subsection{Analisis}

Analisis data adalah tahapan dimana dilakukan analisis terhadap data-data yang akan diolah dalam sistem, dalam hal ini data yang akan diprediksi adalah data jumlah penjualan produk di Ramayana.

\subsection{Backpropagation}

Backpropagation adalah algoritma pembelajaran untuk memperkecil tingkat error dengan cara menyesuaikan bobotbobotnya berdasarkan perbedaan output dan target yang diinginkan. Metode ini bekerja melalui proses secara iteratif dengan menggunakan sekumpulan contoh data (data training), membandingkan nilai prediksi dari jaringan dengan setiap contoh [4].

\subsection{Jaringan Syaraf Tiruan}

Jaringan syaraf tiruan memproses data atau informasi secara paralel dan terdistribusi, hal ini terinspirasi dari model kerja otak biologis. Jaringan syaraf tiruan merupakan salah satu representasi buatan otak manusia yang selalu mencoba untuk mensimulasikan proses pembelajaran pada otak manusia [5]. Jaringan syaraf tiruan didefenisikan sebagai suatu sistem pemrosesan informasi yang memiliki karakteristik menyerupai jaringan syaraf manusia [6]. Jaringan syaraf tiruan adalah sistem komputasi yang arsitektur dan operasinya diilhami dari pengetahuan tentang sel saraf biologis di dalam otak [7].

\subsection{Matlab}

Matlab adalah sebuah program yang digunakan untuk menganalisis dan mengkomputasi data numeric dan juga merupakan bahasa pemrograman matematika lanjutan. Matlab merupakan suatu bahasa pemrograman lanjutan yang dibentuk dengan dasar pemikiran menggunakan sifat dan bentuk dari matriks [8]. Matlab singkatan dari matrix laboratory, dimana matlab merupakan perangkat lunak atau software untuk komputasi teknis dan saintifik [9].

\subsection{Prediksi}

Prediksi adalah kegiatan meramal atau memperkirakan. Prediksi bisa berdasarkan metode ilmiah ataupun berdasarkan subjektif belaka [10]. Hasil prediksi belum tentu benar namun itu bisa menjadi sebuah persiapan untuk menghadapi dugaan-dugaan yang akan terjadi di masa yang akan datang.

\subsection{Penjualan}

Penjualan adalah kegiatan yang dilakukan perusahaan untuk mempertahankan bisnisnya berkembang dan untuk mendapatkan laba yang diinginkan. Kegiatan penjualan merupakan bagian pemasaran yang bertujuan untuk mengadakan pertukaran terhadap suatu produk dari produsen ke konsumen [11].

\subsection{Produk}

Dalam sebuah bisnis produk adalah barang atau jasa yang dapat diperjual belikan. Produk merupakan titik pusat dari kegiatan pemasaran karena produk merupakan hasil dari suatu perusahaan yang dapat ditawarkan ke pasar untuk dikonsumsi. Produk-produk yang biasa diperjual belikan adalah pakaian, alat-alat tulis, elektronik, bahan baku makanan.

\subsection{Kerangka Kerja Penelitian}

Kerangka kerja penelitian yang digunakan dalam menyelesaikan masalah penelitian ini. 


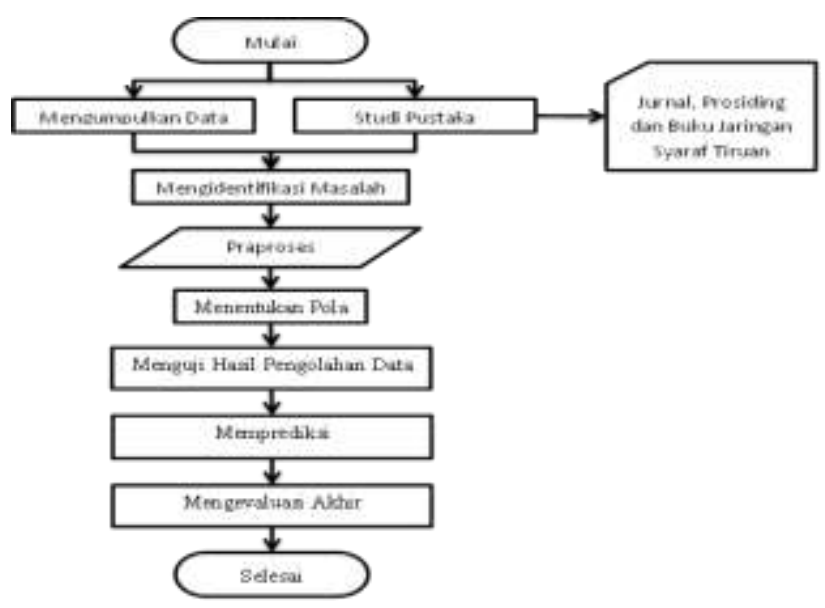

Gambar 1. Kerangka Kerja Penelitian

Berdasarkan kerangka kerja pada gambar diatas maka masing-masing langkah dapat diuraikan sebagai berikut :

a. Mengumpulkan Data

Pada tahap ini, data-data yang digunakan diperoleh dari data jumlah penjualan produk-produk Ramayana Pematangsiantar.

b. Studi Pustaka

Studi pustaka merupakan langkah awal dalam penelitian ini, studi pustaka ini dilakukan untuk melengkapi pengetahuan dasar dan teori-teori yang digunakan dalam penelitian ini. Studi pustaka yang digunakan berasal dari buku, jurnal, dan seminar

c. Mengidentifikasi Masalah

Pada tahap identifikasi masalah ini, dilakukan setelah semua data-data terpenuhi kemudian didapatkan dataset yang sesuai untuk dilakukan proses pada tahap konversi data yang didapat sesuai dengan bobot yang ditentukan.

d. Praproses

Tahapan yang dikerjakan adalah dengan melakukan perubahan terhadap beberapa tipe data pada atribut dataset dengan tujuan untuk mempermudah pemahaman terhadap isi record, juga melakukan seleksi dengan memperhatikan konsistensi data.

e. Menentukan Pola

Hasil dari tahap ini adalah beberapa model jaringan saraf tiruan dengan metode Backpropagation untuk menentukan pola.

f. Menguji Hasil Pengolahan Data

Seteleh proses penentuan pola selesai, maka dilakukan tahapan uji coba terhadap hasil pengolahan data dengan menggunakan Software Matlab R2011b.

g. Memprediksi

Prediksi dilakukan untuk membandingkan jumlah dengan model algoritma Backpropagation yang paling akurat.

h. Mengevaluasi Akhir

Mengevaluasi akhir dilakukan untuk mengetahui apakah testing hasilpengolahan data sesuai dengan yang diharapkan.

\subsection{Data Yang Digunakan}

Data yang digunakan dalam penelitian ini adalah data Jumlah Penjualan Produk-produk Ramayana dari Tahun 2012-2018 (Tabel 1). Data training yang akan digunakan adalah data tahun 2012-2015 dengan target tahun 2018. Sedangkan data testing yang akan digunakan adalah data tahun 2015-2018 dengan target tahun 2018.

Tabel 1. Data Jumlah Penjualan Produk-produk Ramayana

\begin{tabular}{|c|l|l|l|l|l|l|l|l|}
\hline No & Brand & $\mathbf{2 0 1 2}$ & $\mathbf{2 0 1 3}$ & $\mathbf{2 0 1 4}$ & $\mathbf{2 0 1 5}$ & $\mathbf{2 0 1 6}$ & $\mathbf{2 0 1 7}$ & $\mathbf{2 0 1 8}$ \\
\hline 1 & Homyped & 2359 & 2749 & 2614 & 2744 & 2751 & 2264 & 2378 \\
\hline 2 & Bata & 2483 & 2971 & 2595 & 2764 & 2536 & 2736 & 2961 \\
\hline 3 & Carvil & 2903 & 2682 & 2574 & 2446 & 2298 & 2078 & 2338 \\
\hline 4 & Precise & 2177 & 2622 & 2377 & 2685 & 2175 & 2335 & 2485 \\
\hline 5 & Ardiles & 2812 & 2316 & 2021 & 2218 & 2324 & 2572 & 2924 \\
\hline 6 & Cardinal & 2715 & 2509 & 2629 & 2803 & 2191 & 2912 & 2797 \\
\hline 7 & Gabrielle & 2271 & 2404 & 2675 & 2204 & 2751 & 2001 & 2035 \\
\hline 8 & Emba & 2796 & 2626 & 2474 & 2859 & 2193 & 2045 & 2355 \\
\hline 9 & Lois & 2115 & 2427 & 2369 & 2584 & 2985 & 2736 & 2152 \\
\hline
\end{tabular}




\begin{tabular}{|l|l|l|l|l|l|l|l|l|}
\hline 10 & Polo & 2217 & 2185 & 2131 & 2175 & 2169 & 2128 & 2159 \\
\hline 11 & Westpark & 2185 & 2188 & 2156 & 2183 & 2134 & 2072 & 1105 \\
\hline 12 & Tracker & 2107 & 2112 & 2132 & 2172 & 1158 & 2177 & 2428 \\
\hline
\end{tabular}

\subsection{Normalisasi Data}

Sebelum diproses, data dinormalisasi terlebih dahulu dengan menggunakan fungsi Sigmoid (tidak pernah mencapai 0 ataupun 1), maka transformasi data dilakukan pada interval yang lebih kecil yaitu [0.1; 0.9], ditunjukkan dengan persamaan (1).

$$
x^{\prime}=\frac{0.8(x-a)}{b-a}+0.1
$$

Dimana:

$\mathrm{X}^{\prime}$ adalah nilai transformasi dari data

$\mathrm{X}$ adalah data yang akan dinormalisasi

a adalah data minimum pada data input (produk Ramayana)

$\mathrm{b}$ adalah data maximum pada data input (produk Ramayana)

Tabel 2. Normalisasi Data Training

\begin{tabular}{lcccc}
\hline Brand & & Input & & Target \\
& $\mathbf{2 0 1 2}$ & $\mathbf{2 0 1 3}$ & $\mathbf{2 0 1 4}$ & \\
\hline Homyped & 0.38463 & 0.71305 & 0.59937 & 0.70884 \\
Bata & 0.48905 & 0.90000 & 0.58337 & 0.72568 \\
Carvil & 0.84274 & 0.65663 & 0.56568 & 0.45789 \\
Precise & 0.23137 & 0.60611 & 0.39979 & 0.65916 \\
Ardiles & 0.76611 & 0.34842 & 0.10000 & 0.26589 \\
Cardinal & 0.68442 & 0.51095 & 0.61200 & 0.75853 \\
Gabrielle & 0.31053 & 0.42253 & 0.65074 & 0.25411 \\
Emba & 0.75263 & 0.60947 & 0.48147 & 0.80568 \\
Lois & 0.17916 & 0.44189 & 0.39305 & 0.57411 \\
Polo & 0.26505 & 0.23811 & 0.19263 & 0.22968 \\
Westpark & 0.23811 & 0.24063 & 0.21368 & 0.23642 \\
Tracker & 0.17242 & 0.17663 & 0.19347 & 0.22716 \\
\hline
\end{tabular}

Tabel 3. Normalisasi Data Testing

\begin{tabular}{lcccc}
\hline \multicolumn{1}{c}{ Brand } & $\mathbf{2 0 1 5}$ & $\begin{array}{c}\text { Input } \\
\mathbf{2 0 1 6}\end{array}$ & $\mathbf{2 0 1 7}$ & Target \\
\hline Homyped & 0.79745 & 0.80043 & 0.59319 & 0.64170 \\
Bata & 0.80596 & 0.70894 & 0.79404 & 0.88979 \\
Carvil & 0.67064 & 0.60766 & 0.51404 & 0.62468 \\
Precise & 0.77234 & 0.55532 & 0.62340 & 0.68723 \\
Ardiles & 0.57362 & 0.61872 & 0.72426 & 0.87404 \\
Cardinal & 0.82255 & 0.56213 & 0.86894 & 0.82000 \\
Gabrielle & 0.56766 & 0.80043 & 0.48128 & 0.49574 \\
Emba & 0.84638 & 0.56298 & 0.50000 & 0.63191 \\
Lois & 0.72936 & 0.90000 & 0.79404 & 0.54553 \\
Polo & 0.55532 & 0.55277 & 0.53532 & 0.54851 \\
Westpark & 0.55872 & 0.53787 & 0.51149 & 0.10000 \\
Tracker & 0.79745 & 0.80043 & 0.59319 & 0.64170 \\
\hline
\end{tabular}

Cara perhitungan normalisasi dapat dilihat di bawah ini:

$$
x^{\prime}=\frac{0.8(2359-2021)}{950}+0.1=0.38463
$$

Dari perhitungan di atas dapat dijelaskan 2359 diambil dari data asli (Tabel 1), 2021 adalah nilai minimum dari keseluruhan data asli (Tabel 1), 950 diperoleh dari nilai maximum dikurang nilai minimum. Sehingga didapatkan hasil 0.38463 seperti pada Tabel 2.

\section{ANALISA DAN PEMBAHASAN}

Penelitian ini menggunakan 5 arsitektur. Antara lain 3-26-1, 3-31-1, 3-35-1, 3-39-1, 3-40-1. Dari kelima arsitektur ini, arsitektur yang terbaik adalah 3-35-1 dengan tingkat akurasi sebesar 92\% dan epoch sebanyak 1219 iterasi. 


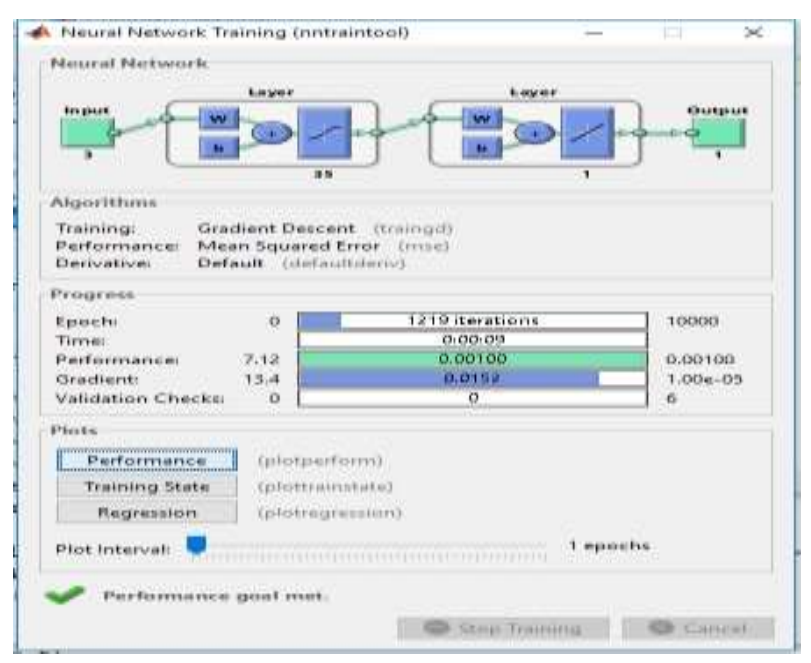

Gambar 2. Hasil Pelatihan Data Dengan Arsitektur 3-35-1

Dari gambar model arsitektur 3-35-1 pada gambar 2 dijelaskan bahwa Epoch yang terjadi sebesar 1219 dengan lama waktu 9 detik.

Tabel 4. Arsitektur JST Backpropagation

\begin{tabular}{ccccc}
\hline & & \multicolumn{3}{c}{ Data Training } \\
No & Target & Output & Error & SSE \\
\hline 1 & 0.7088 & 0.6953 & 0.0135 & 0.00018339 \\
2 & 0.7257 & 0.7382 & -0.0125 & 0.00015664 \\
3 & 0.4579 & 0.4373 & 0.0206 & 0.00042414 \\
4 & 0.6592 & 0.6233 & 0.0359 & 0.00128579 \\
5 & 0.2659 & 0.2624 & 0.0035 & 0.00001221 \\
6 & 0.7585 & 0.7487 & 0.0098 & 0.00009656 \\
7 & 0.2541 & 0.2578 & -0.0037 & 0.00001365 \\
8 & 0.8057 & 0.8290 & -0.0233 & 0.00054363 \\
9 & 0.5741 & 0.6164 & -0.0423 & 0.00178884 \\
10 & 0.2297 & 0.2678 & -0.0381 & 0.00145281 \\
11 & 0.2364 & 0.2629 & -0.0265 & 0.00070113 \\
12 & 0.2272 & 0.1541 & 0.0731 & 0.00533746 \\
& & & Total & 0.01199626 \\
& & & MSE & 0.00099969
\end{tabular}

Tabel 5. Data Testing

\begin{tabular}{cccccc}
\hline No & Target & Output & Error & SSE & Hasil \\
\hline 1 & 0.6417 & 0.6456 & -0.0039 & 0.00001519 & 1 \\
2 & 0.8898 & 0.9388 & -0.0490 & 0.00240225 & 1 \\
3 & 0.6247 & 0.6385 & -0.0138 & 0.00019097 & 1 \\
4 & 0.6872 & 0.7031 & -0.0159 & 0.00025173 & 1 \\
5 & 0.8740 & 0.8781 & -0.0041 & 0.00001646 & 1 \\
6 & 0.8200 & 0.7800 & 0.0400 & 0.00160000 & 1 \\
7 & 0.4957 & 0.4918 & 0.0039 & 0.00001556 & 1 \\
8 & 0.6319 & 0.6139 & 0.0180 & 0.00032454 & 1 \\
9 & 0.5455 & 0.5227 & 0.0228 & 0.00052130 & 1 \\
10 & 0.5485 & 0.4862 & 0.0623 & 0.00388262 & 0 \\
11 & 0.1000 & 0.1510 & -0.0510 & 0.00260100 & 1 \\
12 & 0.6630 & 0.6511 & 0.0119 & 0.00014110 & 1 \\
& & & Total & 0.01196272 & $92 \%$ \\
& & & MSE & 0.00099689 & \\
\hline
\end{tabular}

Ket :

$1=$ Benar $\quad 0=$ Salah

Dari tabel 4 dapat dijelaskan target diambil dari hasil normalisasi, untuk data training diambil dari tahun 2015 dan untuk data testing diambil dari tahun 2018. Output hasil dari pengolahan data menggunakan aplikasi Matlab. Error merupakan hasil pengurangan target 
dan output, SSE hasil pangkat 2 (dua) dari Error dan Hasil didapatkan dari nilai error dimana apabila nilai error lebih kecil sama dengan 0.05 maka hasilnya 1 (benar) jika sebaliknya maka hasilya 0 (salah).

\subsection{Perbandingan Arsitektur}

Penelitian ini menggunakan 5 arsitektur dimana salah satunya merupakan arsitektur terbaik yang akan digunakan untuk mencari hasil prediksi jumlah penjualan produk Ramayana Pematangsiantar untuk tahun berikutnya, berikut adalah perbandingan 5 arsitektur yang digunakan:

Tabel 6. Perbandingan 5 Arsitektur

\begin{tabular}{ccccc}
\hline \multirow{2}{*}{ Arsitektur } & \multicolumn{2}{c}{ Training } & \multicolumn{2}{c}{ Testing } \\
& Epoch & MSE & MSE & Akurasi \\
\hline $3-26-1$ & 1539 & 0.00099855 & 0.00099995 & $75 \%$ \\
$3-31-1$ & 3101 & 0.00099867 & 0.00100030 & $83 \%$ \\
$3-35-1$ & 1219 & 0.00099969 & 0.00099689 & $92 \%$ \\
$3-39-1$ & 2470 & 0.00100072 & 0.00099851 & $83 \%$ \\
$3-40-1$ & 1214 & 0.00099702 & 0.00100046 & $92 \%$ \\
\hline
\end{tabular}

Dari tabel 5 dapat dilihat perbandingan 5 arsitektur yang digunakan dalam penelitian ini. Akurasi yang didapat dari arsitektur 3-35-1 adalah 92\% dan menjadi arsitektur yang terbaik dari arsitektur lainnya.

Tabel 7. Hasil Prediksi 4 Tahun Kedepan (Tahun 2019-2022)

\begin{tabular}{cllccc}
\hline \multirow{2}{*}{ No } & \multirow{2}{*}{ Produk } & \multicolumn{4}{c}{ Jumlah Penjualan Produk (Quantity) } \\
& & $\mathbf{2 0 1 9}$ & $\mathbf{2 0 2 0}$ & $\mathbf{2 0 2 1}$ & $\mathbf{2 0 2 2}$ \\
\hline 1 & Homyped & 2371 & 2403 & 2489 & 2520 \\
2 & Bata & 3051 & 3039 & 3029 & 3096 \\
3 & Carvil & 2354 & 2213 & 2480 & 2578 \\
4 & Precise & 2504 & 2569 & 2618 & 2652 \\
5 & Ardiles & 2910 & 2906 & 2912 & 2831 \\
6 & Cardinal & 2683 & 2721 & 2749 & 2784 \\
7 & Gabrielle & 2014 & 2131 & 2244 & 2374 \\
8 & Emba & 2297 & 2497 & 2411 & 2373 \\
9 & Lois & 2086 & 2145 & 2244 & 2233 \\
10 & Polo & 2001 & 2040 & 2156 & 2293 \\
11 & Westpark & 1223 & 1333 & 1529 & 1699 \\
12 & Tracker & 2384 & 2415 & 2416 & 2605 \\
\hline
\end{tabular}

Dari tabel 6 dapat dilihat hasil prediksi jumlah penjualan produk Ramayana Pematangsiantar untuk periode 2019 2022.

Tabel 8. Perhitungan Hasil Prediksi

\begin{tabular}{ccccc}
\hline 2019 & & & & \\
No & $\begin{array}{c}\text { Data } \\
\text { Real }\end{array}$ & Target & $\begin{array}{c}\text { Target } \\
\text { Prediksi }\end{array}$ & Prediksi \\
\hline 1 & 2378 & 0.6417 & 0.6456 & 2371 \\
2 & 2961 & 0.8898 & 0.9388 & 3051 \\
3 & 2338 & 0.6247 & 0.6385 & 2354 \\
4 & 2485 & 0.6872 & 0.9388 & 2504 \\
5 & 2924 & 0.8740 & 0.8781 & 2910 \\
6 & 2797 & 0.8200 & 0.7800 & 2683 \\
7 & 2035 & 0.4957 & 0.4918 & 2014 \\
8 & 2355 & 0.6319 & 0.6139 & 2297 \\
9 & 2152 & 0.5455 & 0.5227 & 2086 \\
10 & 2159 & 0.5485 & 0.4862 & 2001 \\
11 & 1105 & 0.1000 & 0.1510 & 1223 \\
12 & 2428 & 0.6630 & 0.6511 & 2384 \\
b & 2961 & & & \\
a & 1105 & & & \\
b-a & 1856 & & & \\
\hline
\end{tabular}

Ket $: \mathrm{a}=$ nilai min data real

$\mathrm{b}=$ nilai max data real

Untuk mencari hasil prediksi terlebih dahulu melakukan pergutingan dengan menggunakan rumus berikut ini: 


$$
x^{\prime}=\frac{(x-0.1) *(b-a)}{0.8}+a
$$

Maka diperoleh hasil perhitungan prediksi:

$$
\begin{aligned}
& x^{\prime}=\frac{(0.6456-0.1) *(1856)}{0.8}+1105 \\
& x^{\prime}=2371
\end{aligned}
$$

Dari perhitungan di atas dapat dijelaskan 0.6456 merupakan target prediksi, 1856 merupakan nilai max-min, 1105 merupakan nilai min. Dan didapatkan hasil prediksi dengan jumlah 2371.

\section{KESIMPULAN}

Kesimpulan yang dapat diambil dari penelitian ini antara lain :

1. Dari hasil penelitian dengan percobaan training data didapatkan bahwa arsitektur yang terbaik adalah 3-35-1 dengan akurasi 92\%, MSE training sebesar 0.00099689.

2. Dengan menggunakan arsitektur tersebut, hasil prediksi untuk penjualan produk-produk Ramayana Pematangsiantar pada tahun berikutnya memiliki nilai yang bervariasi dan tidak berjarak sangat jauh dari tahun-tahun sebelumnya.

\section{REFERENCES}

[1] P. G. Frederik, S. C. Nangoy, V. N. Untu, U. Sam, and R. Manado, “ANALISIS PROFITABILITAS , KEBIJAKAN HUTANG DAN PRICE EARNING RATIO TERHADAP NILAI PERUSAHAAN PADA PERUSAHAAN RETAIL TRADE YANG TERDAFTAR DI BURSA EEK INDONESIA," EMBA, vol. 3, no. 1, pp. 1242-1253, 2015.

[2] D. Amanah et al., "Pengaruh Promosi dan Brand Image (Citra Produk) Terhadap Loyalitas Pembelian Produk Pepsodent di Ramayana Plaza, Jalan Aksara, Medan,” Keuang. Bisnis, vol. 3, no. 3, pp. 221-233, 2011.

[3] S. Hansun, "Peramalan Data IHSG Menggunakan Metode Backpropagation," Univ. Multimed. Nusant., vol. IV, no. 1, pp. 26-30, 2013.

[4] A. Novita, "Prediksi Pergerakan Harga Saham Pada Bank Terbesar Di Indonesia Dengan Metode Backpropagation Neural Network," JUTISI, vol. 5, no. 1, pp. 965-972, 2016.

[5] Solikhun, A. P. Windarto, Handrizal, and M.Fauzan, "JARINGAN SARAF TIRUAN DALAM MEMPREDIKSI SUKUK NEGARA RITEL BERDASARKAN KELOMPOK PROFESI DENGAN BACKPROPOGATION DALAM MENDORONG LAJU PERTUMBUHAN EKONOMI," Pros. Semin. Ilm. Nas., pp. 14-31, 2017.

[6] A. Jumarwanto, R. Hartanto, and D. Prastiyanto, “APLIKASI JARINGAN SARAF TIRUAN BACKPROPAGATION UNTUK MEMPREDIKSI PENYAKIT THT DI RUMAH SAKIT MARDI RAHAYU KUDUS,” Tek. Elektro, vol. 1, no. 1, pp. 11-21, 2009.

[7] D. C. Febrianto, "Penerapan Jaringan Saraf Tiruan dengan Metode Pembelajaran Backpropagation untuk Mengetahui Tingkat Kualifikasi Calon Siswa pada Sistem Informasi Penerimaan Siswa Baru di MAN 2 Banjarnegara Backpropagation Learning Method to Find Out the Level of Qualific," JUITA, vol. II, pp. 189-197, 2013.

[8] S. Desmanto, Irwan, and R. Angreni, "Penerapan Algoritma K-Means Clustering Untuk Pengelompokkan Citra Digital Dengan Ekstraksi Fitur Warna RGB," vol. 1, no. 2, pp. 1-9, 2014.

[9] E. H. Ratama, "Politeknik Negeri Sriwijaya," vol. 1, no. 4, pp. 5-24, 2015.

[10] N. Aini, S. Sinurat, and S. A. Hutabarat, "Penerapan Metode Simple Moving Average Untuk Memprediksi Hasil Laba Laundry Karpet Pada CV . Homecare," vol. 5, no. 2, pp. 167-175, 2018.

[11] Afrianto, "ANALISIS PENJUALAN PT . SUKA FAJAR LTD DALAM MENINGKATKAN VOLUME PENJUALAN PRODUK MITSUBISHI DI RIAU ( STUDI KASUS MINIBUS ) UNIVERSITAS ISLAM NEGERI MENINGKATKAN VOLUME PENJUALAN PRODUK MITSUBISHI DI RIAU ( STUDI KASUS MINIBUS ),” vol. 1, no. 1, pp. 1-84, 2011. 